\title{
Introduction to the preservation of cultural heritage
}

\author{
Marianne Odlyha
}

Received: 15 February 2011/ Accepted: 18 February 2011/Published online: 18 March 2011

(C) Akadémiai Kiadó, Budapest, Hungary 2011

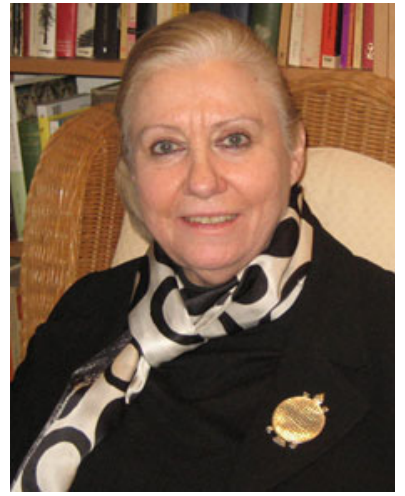

This special chapter focuses on the contribution of thermal analysis to the preservation of cultural heritage and its continuing vital role. Case studies outlining the use of these techniques have been reported in chapters in "Modern Analytical Methods in Art and Archaeology" [1] and in the "Handbook of Thermal Analysis and Calorimetry", respectively [2]. In both, reports of collaborative projects with major museums, art galleries, and conservation centres were described, and included the application of the full range of thermoanalytical techniques, differential scanning calorimetry (DSC), thermogravimetry (TG), thermomechanical analysis (TMA), dielectric analysis, dynamic mechanical analysis (DMA), and micro-thermal analysis ( $\mu$-TA).

The last decade has seen a steady increase in the contribution of advanced analytical techniques, including thermal analysis, as concern for the preservation of cultural

\section{Odlyha ( $\square)$}

Institute of Structural and Molecular Biology, Department of Biological Sciences, Birkbeck, University of London, Malet St., London WC1E 7HX, United Kingdom

e-mail: m.odlyha@bbk.ac.uk heritage and its sustainability increases, in the face of effects of climate change and the potential threat it poses to the sustainability of Europe's cultural heritage. In view of this, one of the main issues is assessment of levels of risk to the built environment and to the valuable collections of heritage objects in museums, art galleries, and libraries. This requires knowledge of the quality of the existing outdoor environment and for objects, the indoor environments in which they are displayed or stored. The level of corrosivity will be influenced by the ingress of pollutants from the external environment and any contributions from indoor sources. It is also necessary to have an understanding of how damage to cultural heritage occurs, and how these processes can be retarded to ensure that the objects are protected. Thermal analysis offers methods for problem solving in this area and evidence of this is in a recent article [3] and then the current collection of articles in this chapter which reflect areas of investigation performed in both outdoor and indoor environments, and include characterization of materials used in historic buildings, artefacts in outdoor cultural heritage, ceramics, wood used in cultural heritage, historical parchment in archival collections, and paint media analysis.

In the introduction to this chapter examples of the application of thermal analysis to preventive conservation and risk assessment will be given. This will be followed by some examples of the use of thermal analysis for damage assessment of objects and evaluation of environmental effects and conservation treatment. Techniques such as controlled environment DMA and nanoscale techniques of atomic force microscopy (AFM) and $\mu$-TA have been used.

The quality of environments and the effect of environmental factors such as light, relative humidity, and pollutants on objects both in outdoor and indoor environments 
are studied in preventive conservation. To achieve this, monitoring is performed of the microclimate surrounding the object using both diffusive passive samplers and dosimeters. Such a study was performed in the PROPAINT project "Improved protection of paintings during exhibition, storage and transit" (EU 6th Framework Programme http://propaint.nilu.no), where the corrosivity of the microclimate within and outside frames containing paintings was monitored [4]. The results obtained using passive samplers showed that levels of inorganic pollutants were lower inside the frames than outside, whereas the levels of volatile organic compounds (VOCs) such as ethanoic acid, methanoic acid, toluene, $\alpha$-pinene were higher [5]. Studies were also performed of paintings within transit frames given the emphasis on loans of collections for major exhibitions. The levels of VOCs raised concern about the possible long term deleterious effect on varnishes on paintings. Accelerated ageing tests were performed within the PROPAINT project of the effect of ethanoic acid at various concentrations and relative humidity values on natural triterpenoid varnishs (resin mastic and dammar) and synthetic varnishes (MS2A a reduced ketone resin, Paraloid B72 an acrylic resin). Changes were evaluated using DMA, mass spectrometry, AFM and $\mu$-TA. Results are reported in the PROPAINT project final report which is accessible on the project website (http://propaint.nilu.no). Work is in progress within the current MEMORI (Measurement, Effect Assessment and Mitigation of Pollutant Impact on Movable Cultural Assets) project (EU 7th Framework) to determine threshold levels of damage of organic pollutants (ethanoic and methanoic acids) on organic objects. Preliminary data obtained in the PROPAINT project showed that for the extreme case where dammar varnish was exposed to glacial acetic acid a large shift in $T_{\mathrm{g}}$ occurred with significant changes at the molecular level. This illustrates the value of $T_{\mathrm{g}}$ measurement in preventive conservation as a marker of damage due to the corrosive activity of the microclimate to which the varnish is exposed. The objectives of the MEMORI project follow the requirements of EU 7th Framework programmes for improved understanding of the mechanisms by which damage to cultural heritage occurs, and for optimizing procedures to ensure that tangible cultural heritage is protected.

Dosimeters are increasingly used in preventive conservation since they integrate the combined effects of the environmental factors and provide an early warning signal of the degree of corrosivity of the microclimate surrounding heritage objects. An example of the application of thermal analysis in evaluation of paint dosimeters is given by the work performed in the ERA (Environmental Research for Art Conservation), a 4th EC Framework project (EV5VCT94 0548). Mock paintings were prepared and DSC, TG and DMA together with FTIR and mass spectrometric techniques were used to assess the changes on accelerated ageing of the paint and on site exposure to selected and different environments for a period of 9 months [6]. The paint strips were prepared according to traditional paint tempera preparations using a selection of pigments on a polyester substrate. They showed differences in behaviour according to pigment type which was influenced by the reactivity of the pigment and its effect on the paint media in terms of crosslinking and thermal stability. This was the first time that DMA had been used on egg tempera paint films and the glass transition of the lipid component and the effect of the various inorganic pigments such as smalt (cobalt oxide glass) and azurite (basic copper carbonate) was measured. It was also found that differently pigmented strips had differing sensitivities to light and $\mathrm{NO}_{x} \mathrm{SO}_{2}$. After site exposure ranking of extent of damage was made and this exceeded measured changes in the accelerated aged samples and illustrated the synergistic effects of environmental parameters acting on the paint dosimeters and that the levels of inorganic pollutants contributed to the damage. As expected changes at sites where there was little or no control of the environment occurred to a greater extent than in environments where conditions were controlled [7].

Other workers have also reported thermo-oxidative studies using DSC to show differences in the thermal stabilities of the prepared paint films, and those previously exposed to UV and $\mathrm{NO}_{x}$ [8]. In this article, DSC was also used with TG for testing prepared oil paint films, glue and resins and to study film formation of tung oil and Chinese lacquer.

Preventive conservation also concerns itself with the nature of storage facilities. A common storage system for archaeological iron used within English Heritage makes use of plastic containers (Stewart boxes) with silica gel. A recent study described how the performance of the boxes was evaluated by monitoring the relative humidity and levels of pollutants within the boxes, and measuring their air exchange rates [9]. Spectroscopic (FTIR) analysis together with DSC was used to determine the state of preservation of the polyethylene and polypropylene-based storage boxes. Small samples were removed for determination of the degree of crystallinity (\%) of the polymers. Deterioration of the boxes could have adverse effects on storage microenvironment and the stored archaeological iron. This could cause splitting of the lids and loss of efficiency of the box seals which would reduce their protective effect and the lifetime of the silica gel. In addition, any deterioration will possibly release VOCs and such compounds could reach significant levels in enclosures. The presence of certain compounds could well accelerate the deterioration reactions of the stored archaeological iron or other metal artifacts. The stabilization of archaeological 
iron has presented serious problems for conservators and work is in progress to optimize procedures. Studies have reported the post excavation changes which occur and which involve the formation of $\beta-\mathrm{FeOOH}$, akaganéite. TG and MS analysis of akaganéite has been reported [10] together with crystallographic studies and Mössbauer spectroscopy. The detection of akaganéite has been considered relevant to the stability of archaeological iron objects on display and in storage. This is the subject of the Ph.D thesis "Post excavation Changes and Preventive Conservation of Archaeological Iron" (in preparation) by David Thickett, senior conservation scientist at English Heritage.

Knowledge of the physico-chemical state of the object, and particularly of any visible alteration products which form on display or in storage environments is also essential to preventive conservation. A recent study was made on the black crust removed from historic buildings in two Italian towns (Pisa and Ravenna). Sampling in Pisa included sampling from the Leaning Tower of Pisa. The composition of the black crusts containing gypsum and carbonates was closely related to the characteristics and levels of pollution in the surrounding environment [11]. It was demonstrated that thermal analysis was suitable for discrimination and measurement of the carbon fraction in damaged layers on buildings. Moreover, the ratio between organic and elemental carbon content showed a difference between the two sites indicating that where variability in the ratio occurred then the organic fraction was not exclusively attributed to combustion emissions. It was concluded that the availability of suitable analytical methodologies, and in this case the innovative use of thermal analysis, was important not only in assessment of damage to monuments and historical buildings but also in defining a sustainable protection and maintenance of cultural heritage. The project CARAMEL (Carbon content and origin of damage layers in European monuments) was supported in part by the EC, 5th Framework within the Environment and Sustainable Development Programme Project (Contract no. EVK4-CT-2000-00029).

Physico-chemical characterization of artefacts also contributes to the understanding the early technologies as described in the thermal analysis study of samples from the terracotta warriors of the Qin Dynasty. Here, techniques of TG, DSC, TMA and X-ray diffraction were used to characterize the composition of terracotta (Qin dynasty) and then TMA and thermomagnetometry were used to demonstrate that the material had not been previously fired to temperatures above $600{ }^{\circ} \mathrm{C}$ [12]. The presence of a ferromagnetic component showed a difference in the TG curve in the presence and absence of a magnetic field. Above $600{ }^{\circ} \mathrm{C}$ which is also above the Curie temperature of magnetite the TG curve showed identical behaviour.
Thermomagnetometry has also been used to study mineralized archaeological iron samples from the 4th century $\mathrm{AD}$ cart burial from East Yorkshire, UK [13].

An example on the effect of environmental factors of indoor cultural heritage is given by a study of leather bookbindings which were stored in differing locations, the British Library, London and in Aberystwyth, Wales. Thermomicroscopy (or Micro Hot Table) was used to test the shrinkage characteristics of fibres sampled from the bookbindings, and additional analysis involving amino acid analysis, measurement of $\mathrm{pH}$, and content of sulphate and tannins was also performed. Measured differences correlated with the higher levels of pollutants in the central London location of the British Museum, and it was found that shrinkage temperature was a useful parameter in the modelling of the average breakdown profile of leathers [14]. The work on collagen-based materials continued with parchment within the framework of two EU projects, MAP (Microanalysis of Parchment) [15] and IDAP (Improved Damage Assessment of Parchment) [16]. Parchment, like leather, is also made from animal skin but differs from leather in that it is not treated with tannins. Large collections of parchment documents exist in public and private libraries, archives and religious institutions which are recognized as being amongst the most valuable objects of our cultural heritage. The main aim of the IDAP project was to develop and optimize methods for damage assessment. Accelerated ageing of new parchment using gaseous pollutants $\left(\mathrm{NO}_{2}, \mathrm{SO}_{2}\right.$ and mixed gases) as well as thermal and light ageing was performed and resulting samples investigated by DSC. This is the first time that a in depth study of pollutant ageing together with heat and light on parchment has been performed and results provided a useful basis for assessment of level of damage [17].

Atomic force microscopy and micro-thermal analysis were then used to develop procedures for damage assessment at the nanoscale level. Some correlation was found between measured shrinkage temperature, as determined by thermomicroscopy, with the degree of retention of the periodic collagen D-banding (AFM), and thermal degradation behaviour at the micro-scale ( $\mu$-TA). Controlled environment DMA was also used to study the change in mechanical properties (modulus, displacement) of dried parchment with increase in $\mathrm{RH}$, and some correlation was found between AFM and $\mu$-TA, displacement with increase in RH, and shrinkage temperature [18]. This approach has also been used to study samples from historical tapestries and accelerated aged wool and silk samples [19]. So these examples show that thermal analysis can contribute in several ways to damage assessment and contribute to further preservation of the objects.

The application to modern plastics has also received attention. Recent study has reported on the application of 
chemical and thermal analysis methods for studying cellulose ester plastics [20]. Results from this study form the basis for studies of art works made from cellulose acetate. The point is also made that these objects require particular attention from conservators, particularly if stored in tightly sealed containers, as the release of volatile gaseous products (ethanoic acid in the case of cellulose acetate) will accelerate degradation processes and lead to sudden onset of deterioration, as observed with photographic film. Another example can be found in synthetic polyamides used in heritage textile collections frequently in combination with natural organic materials. For preservation they are often exposed to the same pest treatments as natural polymers, which includes lowering or raising the temperature. In addition if treated whilst the textile is hanging the additional load may have an effect. Analysis of the data obtained indicated that observed changes could be related to alterations in the degree of crystallinity produced by changes in temperature and the presence of stress during the treatment [21]. The notion of crystallization as a cause of damage was also the outcome of a recent study made on the suits worn by astronauts during launch and landing phases [22].

Thermogravimetric studies of wood used in cultural heritage are described in one of the articles in this chapter. Recent application of controlled environment DMA has shown that different types of wood (oak, pine) have differences in their mechanical response to programmed increase and decrease in $\mathrm{RH}$, and for pine there was a measurable difference in the radial and tangential directions. These results obtained by the author were presented (also accepted as paper http://www.woodculther.org/) at the International Conference held by COST Action IE0601-Wood Science for Conservation of Cultural Heritage in Izmir (Turkey) 20-22 October 2010. Examples of use of oak and pine in heritage objects can be found in the windchest of organs, and in panels of paintings. Measurements were also made on gilded pine wood, and differences between gilded and ungilded samples were observed. Another interesting application of DMA related to wood was the investigation of the viscoelastic characteristics of resins and oils that are commonly used for varnishing violins. From the viscoelastic characterization, a simplified model was used to understand the relationship between the physico-chemical properties of isolated simple varnishes and the mechanical characteristics of samples of varnished woods [23].

Thermal analysis in combination with other techniques has also been used to test the effects of conservation treatment. Examples include the following: optimizing firing treatment of cuneiform tablets [24], monitoring effects of solvent and aqueous cleaning of prepared oil [25] and acrylic paint films [26], testing effect of humidification of painted canvases [27] and the effect of deacidification of painting canvases [28]. Canvas, like paper, consists principally of cellulose, and on ageing depolymerization of cellulose fibres occurs which is promoted by acidic conditions. In recent years hydroxide nanoparticles have been used for deacidification of paper and canvas [29]. Calcium hydroxide particles, once deposited onto paper cellulose fibres, deacidify them and react with carbon dioxide from the air, forming a calcium carbonate reservoir on the fibres. Work is in progress by the author using controlled environment DMA to test the effect of deacidification using nanoparticles on the mechanical properties of painting canvases and their response to variations in relative humidity.

The work mentioned in this introductory section has demonstrated the wealth of applications using thermal analysis in the area of cultural heritage, also with complementary advanced analytical techniques. The study has also demonstrated that the applications cover a wide range of materials which occur in outdoor and indoor environments, and the potential of relatively new techniques such as $\mu$-TA for spatially resolved thermal analysis.

\section{References}

1. Odlyha M. Thermal analysis. In: Ciliberto E, Spoto G, editors. Modern analytical methods in art and archaeology. New York: Wiley; 2000. p. 279-315.

2. Odlyha M. The application of thermoanalytical techniques to the preservation of art and archaeological objects. In: Brown ME, Gallagher PK, editors. Handbook of thermal analysis and calorimetry. New York: Elsevier; 2003. p. 47-92.

3. Pires J, Cruz AJ. Techniques of thermal analysis applied to the study of cultural heritage. J Therm Anal Calorim. 2007;87:411-5.

4. Gronthoft T, Odlyha M, Mottner P, Dahlin E, LopezAparicio S, Jakiela S, Scharff M, Andrade G, Obarzanowski M, RyhlSvendsen M, Thickett D, Hackney S, Wadum J. Pollution monitoring by dosimetry and passive diffusion sampling for evaluation of environmental conditions for paintings in microclimate frames. J Cult Herit. 2010;11:411-9.

5. Lopez-Aparicio S, Gronthoft T, Odlyha M, Dahlin E, Mottner P, Thickett D, Ryhl-Svendsen M, Schmidbauer N, Scharff M. Measurement of organic and inorganic pollutants in microclimate frames for paintings. e-PS. 2010;7:59-70.

6. Odlyha M, Boon JJ, van den Brink O, Bacci M. Environmental research for art conservation (ERA). J Therm Anal Calorim. 1997;49:1571-84.

7. Odlyha M, Cohen NS, Foster GM. Dosimetry of paintings: determination of the degree of chemical change in museum exposed test paintings (smalt tempera) by thermal analysis. Thermochim Acta. 2000;365:35-44.

8. Prati S, Chiavari G, Cam D. DSC application in the conservation field. J Therm Anal Calorim. 2001;66:315-27.

9. Thickett D, Odlyha M. Assessment of dry storage microenvironments for archaeological iron. In: Williams E, Peachey C, editors. The conservation of archaeological materials: current trends and future directions. London: Archaeopress; 2010. p. 187-99. 
10. Stahl K, Nielsen K, Jiang J, Lebech B, Hanson JC, Norby P, van Lanshot J. On the akaganéite crystal structure, phase transformations and possible role in post-excavational corrosion of iron artefacts. Corros Sci. 2003;45:2563-75.

11. Ghedini N, Sabbioni C, Pantani M. Thermal analysis in cultural heritage safeguard: an application. Thermochim Acta. 2003;406: $105-13$.

12. Wiedemann HG, Boller A, Bayer G. Thermoanalytical investigations on terracotta warriors of the Qin Dynasty. In: Sayre EV, Vandiver P, Druzik J, Stevenson C, editors. Materials issues in art and archaeology, materials research society symposium proceedings 123. Pittsburgh: Materials Research Society; 1988. pp. 129-134.

13. Thickett D, Odlyha M. Application of thermomagnetometry to corrosion studies of archaeological iron. J Therm Anal Calorim. 2005;80:565-71.

14. Larsen R. Experiments and observations in the study of environmental impact on historical vegetable tanned leathers. Thermochim Acta. 2000;365:85-99.

15. Odlyha M, Cohen N, Foster G, Campana R. In: Larsen R, editor. Characterisation of historic and unaged parchments using thermomechanical and thermogravimetric techniques in microanalysis of parchment (MAP). London: Archetype Publications; 2002. p. $73-80$.

16. Larsen R. Improved damage assessment of parchment (IDAP) assessment, data collection and sharing of knowledge", European Commission Research Report No. 18 (2007) ISBN 978-92-7905378-8.

17. Budrugeac P, Badea E, Della Gatta G, Miu L, Comãnescu A. A DSC Study of deterioration caused by environmental chemical pollutants to parchment, a collagen-based material. Thermochim Acta. 2010;500:51-62.

18. Odlyha M, Theodorakopoulos C, de Groot J, Bozec L, Horton M. Fourier transform infra-red spectroscopy (ATR/FTIR) and scanning probe microscopy of parchment. e-PS. 2009;6:138-44.

19. Odlyha M, Wang Q, Foster GM, de Groot J, Horton M, Bozec L. Thermal analysis of model and historic tapestries. J Therm Anal Calorim. 2005;82:627-36.
20. Schilling M, Bouchard M, Khanjian H, Learner T, Phenix A, Rivenc R. Application of chemical and thermal analysis methods for studying cellulose ester plastics. Acc Chem Res. 2010;43: 888-96.

21. Richardson E. Investigating the characterisation and stability of polyamide 6,6 in Heritage Artefacts, Ph.D thesis, University of Southampton; 2010. (http://eprints.soton.ac.uk/165513/1.has CoversheetVersion/thesis.pdf). Accessed 28 Jan 2011.

22. Wingard D. Use of DSC and DMA to study crystallization as a possible cause for a glove tear. J Therm Anal Calorim. 2010; 102:469-76.

23. Simmonet C, Gibiat V, Halary J-L. Physical and chemical properties of varnishes and their vibrational consequences, PACS reference 4375 DE. (http://www.seaacustica.es/Sevilla02/ musgen002.pdf).

24. Thickett D, Odlyha M, Ling D. An improved firing treatment for cuneiform tablets. Stud Conserv. 2002;47:1-11.

25. Hedley G, Odlyha M, Burnstock A, Tillinghast J, Husband C. A study of the mechanical and surface properties of oil paint films treated with organic solvents and water. J Therm Anal. 1991;3 $7: 2067-88$.

26. Ormsby B, Foster G, Learner T, Ritchie S, Schilling M. Improved controlled relative humidity dynamic mechanical analysis of Artists' acrylic emulsion paints. Part 11. General properties and accelerated ageing. J Therm Anal Calorim. 2007;90:503-8.

27. Odlyha M, Chan TYA, Pages O. Evaluation of relative humidity effects on fabric-supported paintings by dynamic mechanical and dielectric analysis. Thermochim Acta. 1995;263:7-21.

28. Odlyha M, Foster G, Townsend J, Hackney S. Dynamic mechanical analysis for the evaluation of deacidification treatment of painting canvases. J Therm Anal Calorim. 1997;50:191-202.

29. Baglioni P. Nanotechnologies for conservation of cultural heritage: paper and canvas deacidification. Langmuir. 2002;18(21): 8198-203. 